\title{
How Ventilation Is Delivered During Cardiopulmonary Resuscitation: An International Survey
}

\author{
Ricardo Luiz Cordioli MD PhD, Laurent Brochard MD, Laurent Suppan MD, \\ Aissam Lyazidi PhD, François Templier MD, Abdo Khoury MD, Stephane Delisle RRT PhD, \\ Dominique Savary MD, and Jean-Christophe Richard MD PhD
}

\begin{abstract}
BACKGROUND: Recommendations regarding ventilation during cardiopulmonary resuscitation (CPR) are based on a low level of scientific evidence. We hypothesized that practices about ventilation during CPR might be heterogeneous and may differ worldwide. To address this question, we surveyed physicians from several countries on their practices during CPR. METHODS: We used a Web-based opinion survey. Links to the survey were sent by e-mail newsletters and displayed on the Web sites of medical societies involved in CPR practice from December 2013 to March 2014. RESULTS: 1,328 surveys were opened, and 548 were completed (41\%). Responses came from 54 countries, but $64 \%$ came from 6 countries. Responders were mostly physicians $(\mathbf{8 9 \%})$. From this group, $97 \%$ declared following specific CPR guidelines. Regarding practices, $28 \%$ declared always or frequently adopting only continuous chest compressions without additional ventilation. With regard to mechanical chest compression devices, $38 \%$ responded that such devices were available to them; when used, $28 \%$ declared always or frequently experiencing problems with ventilation such as frequent alarms. During bag-mask ventilation in intubated patients, $18 \%$ declared stopping chest compression during insufflation, and 39\% applied $>10$ breaths/min, which conflicts with international CPR guidelines. When a ventilator was used, the volume controlled mode was the most common strategy cited, but there was heterogeneity regarding ventilator settings for PEEP, trigger, $\mathrm{F}_{\mathrm{IO}_{2}}$, and breathing frequency. $\mathrm{S}_{\mathrm{pO}_{2}}$ and end-tidal $\mathrm{CO}_{2}$ were the 2 most monitored variables cited. CONCLUSIONS: Physicians indicated heterogeneous practices that often differ significantly from international CPR guidelines. This may reflect the low level of evidence and a lack of detailed recommendations concerning ventilation during CPR. Key words: ventilation; cardiac arrest; cardiopulmonary resuscitation; mechanical chest compression; manual chest compression; chest compression; survey; practices. [Respir Care 2018;63(10):1293-1301. (C) 2018 Daedalus Enterprises]
\end{abstract}

\section{Introduction}

The ventilatory strategy used during cardiopulmonary resuscitation (CPR) could influence the chance of survival

Dr Cordioli is affiliated with Hospital Israelita Albert Einstein, Intensive Care Unit, Sao Paulo, Brazil, and Hospital Alemão Oswaldo Cruz, Intensive Care Unit, Sao Paulo, Brazil. Dr Brochard is affiliated with the Keenan Research Centre, Li Ka Shing Knowledge Institute, St. Michael's Hospital, Toronto, Canada, and the Interdepartmental Division of Critical Care Medicine, University of Toronto, Toronto, Ontario, Canada. Dr Suppan is affiliated with Geneva University Hospitals, Division of Emergency Medicine, Geneva, Switzerland. Dr Lyazidi is affiliated with Institut Supérieur des Sciences de la Santé, Laboratory Rayonnement- because it can interfere with chest compressions. Recommendations regarding ventilation during CPR in CPR guidelines are weak and are based on relatively low levels of evidence..$^{1-4}$

Matiére et Instrumentation, Université Hassan 1er, Settat, Morocco. Dr Templier is affiliated with University Hospital of Angers, SAMU 49, Emergency Department, Angers, France. Dr Khoury is affiliated with University Hospital of Besançon, Besançon, France. Dr Delisle is affiliated with Hôpital du Sacré-Cœur de Montréal, Service des Soins Intensifs, Québec, Canada. Drs Savary and Richard are affiliated with General Hospital of Annecy, SAMU 74 and Emergency Department, Annecy, France. Dr Richard is also affiliated with INSERM UMR 955 Eq13 Créteil, France. 
In the past, ventilation was the first action to be adopted during CPR. ${ }^{5,6}$ All guidelines published between 1974 and 2005 advocated the famous ABC sequence (A, airway; B, breathing and $\mathrm{C}$, circulation) during the rescue of a victim of cardiac arrest (see the supplementary material at http:// www.rcjournal.com). The importance of ventilation decreased progressively in these guidelines over time, ${ }^{7}$ and the international CPR guidelines published in 2010 changed the former $\mathrm{ABC}$ sequence to $\mathrm{CAB} \cdot{ }^{1-4}$

Some authors advocate only performing chest compressions during CPR, without ventilation, with the goal to provide better neurological outcomes. This strategy is advocated for the general public. Once at least 2 health care professionals are involved, airway opening and breathing should be performed according to international CPR guidelines. ${ }^{1-4}$ Physiological interactions between ventilation and circulation may also differ when chest compression is done manually or with automated devices.

Due to a lack of sufficient evidence in the literature, clinicians are often left with doubts about how ventilation should be performed. ${ }^{9-11}$ Heterogeneity of ventilation practices during CPR is therefore likely to occur. Because ventilation practices may affect outcomes, we conducted an international survey to assess opinions regarding the practices specifically related to ventilation during CPR in adult victims of a non-traumatic cardiac arrest.

\section{Methods}

\section{Instrument}

We used a mixed-methods approach to develop our questionnaire, taking into account the current international CPR guidelines. ${ }^{1-4}$ The first version of our questionnaire was created after discussion among 3 critical care physicians working in Europe, 1 physician in Brazil, and 2 emergency department physicians in Switzerland. We intentionally sampled participants to represent different practice settings. We developed a draft questionnaire, which we piloted among a focus group of 5 physicians from different

\footnotetext{
Dr Richard has disclosed relationships with Air Liquide Medical Systems, Vygon, Dräger, and Covidien. Dr Brochard has disclosed relationships with Maquet, Covidien, Dräger, Philips Respironics, Air Liquide, and General Electric. Dr Khoury has disclosed a relationship with the European Commission.
}

Supplementary material related to this paper is available at http:// www.rcjournal.com.

Correspondence: Ricardo Luiz Cordioli MD PhD, Hospital Israelita Albert Einstein, Av Albert Einstein, 627 - Morumbi 05652-900, Sao Paulo, Brazil. E-mail: rlcordioli@gmail.com.

DOI: $10.4187 /$ respcare. 05964

\section{QUICK LOOK}

\section{Current knowledge}

Assisted ventilation is an important aspect of cardiopulmonary resuscitation (CPR) because it can directly influence survival through positive or negative interactions with chest compression. International guidelines, however, are supported by a low level of evidence and practice heterogeneity is expected.

\section{What this paper contributes to our knowledge}

This survey showed that practices regarding the combination of assisted ventilation with chest compressions during CPR were heterogeneous and often differed significantly from CPR guidelines. Difficulties related to ventilation were reported to be high.

regions in France with experience in CPR. A subsequent draft questionnaire underwent a review process by 20 physicians who participated in the acute respiratory failure meeting group or the trauma and emergency medicine meeting group during the 2013 European Society of Intensive Care Medicine Congress in Paris, France. The final version (see the supplementary material at http://www.rcjournal) was hosted on a Web platform (http://www.cardiomobile.ch), and several physicians from different regions in France tested it.

Survey responses were closed, and response options varied, including multiple choice, single choice on a 4-point response scale (never, rarely, frequently, or always), and Yes/No answers. Some questions were only available depending on specific answers related to accessibility or practices.

This survey was voluntary and anonymous, and additional consent was not required according to Swiss regulatory rules.

\section{Subjects}

Professionals involved in resuscitation teams, including physicians, nurses, respiratory therapists, and paramedics, were considered as potential responders about the way they manage ventilation and chest compression in adult victims of a non-traumatic cardiac arrest.

\section{Survey Administration}

An invitation was sent to members of different national or European societies involved in CPR, and a link to the self-administered survey was available on the Web sites of these societies. The survey could be completed from December 2013 to March 2014. A reminder invitation was sent twice during this period. 


\section{International Survey of Ventilation Delivery DuRing CPR}

\section{Analysis}

Only fully completed surveys were analyzed. We elected a priori to include only those respondents who reported being clinically active in performing CPR.

\section{Results}

\section{Survey Participation}

Of the 1,328 surveys opened, $548(41 \%)$ were completed. Responses came from 54 countries, but most answers (64\%) came from 6 countries: France (25\%), Japan (14\%), Brazil (11\%), Belgium (9\%), and Canada (5\%).

\section{Respondents}

The great majority of responders were physicians (490 of 548 respondents, $89 \%)$, while nurses $(40,7 \%)$, paramedics $(11,2 \%)$, and respiratory/physical therapists $(7,1 \%)$ represented a small proportion coming from only 3 countries. We thus decided to analyze only physicians' responses $(n=490)$ for more consistency and representativeness.

In this group, 55\% (270 of 490 physician respondents) worked in a university hospital, 35\% (170 respondents) declared having a clinical activity in the pre-hospital emergency field, and 54\% (265 respondents) said they had some activity in the ICU setting.

\section{Equipment Available for Ventilation and Chest Compression}

Almost all physicians (479 of 490 respondents, 98\%) affirmed having a bag-mask, which was cited to be the only device available by 19\% (94 respondents); 74\% (363 respondents) declared having a ventilator, and 7\% (33 respondents) said they had a Boussignac CPR tube (Vygon, Ecouen, France) available for CPR.

Concerning chest compression, 38\% (186 of 490 respondents) declared having a specific external pump mechanical device; $24 \%$ (116 respondents) declared having a piston chest compression (LUCAS-CPR, Physio Control, Lund, Sweden; or Thumper Mechanical CPR device, Michigan Instruments, Michigan); 12\% (61 respodents) had an automated load-distributing band (AutoPulse, Zoll, Chelmsford), and 2\% (9 respondents) answered that they had a manual mechanical chest compression device available (AMBU CardioPump, AMBU Company, Copenhagen, Denmark). Finally, 7\% (32 respondents) said they had $>1$ mechanical device available for chest compression. A total of 211 physicians $(43 \%)$ declared belonging to a center engaged in nonheart-beating organ donation. In this subgroup, the availability of an automatic mechanical chest compression device was higher (97 respondents, $44 \%$ ) as well as the probability to use it, according to $60 \%$ (58 respondents) who preferred using mechanical chest compression device over manual chest compression.

\section{Practices and Organization}

General. Almost all physicians (475 of 490 respondents, 97\%) declared following specific CPR guidelines; 73\% (11 of 15 respondents) of those who did not follow a CPR guideline belonged to a non-university hospital. The European Resuscitation Council guidelines were the most cited (232 of 475 respondents, 49\%), followed by the American Heart Association guidelines (38\%) and national guidelines $(11 \%)$; hospital-specific protocols were scarcely cited (2\%).

Basic Life Support. Among the physicians who completed the survey, 28\% (138 of 490 respondents) answered always or frequently adopting the strategy of only continuous chest compression without any additional form of ventilation, especially at the beginning of resuscitation when the rescuer is alone.

For non-intubated patients, when CPR was performed with an automated chest compression device (LUCAS/AutoPulse), $68 \%$ (103 of 152 respondents) declared always or frequently applying the 30:2 option to ventilate the patient with a bagmask device; when a supraglottic airway was inserted (eg, laryngeal mask airway), only $36 \%$ of the physicians (55 of 152 respondents) answered always or frequently applying the 30:2 option to ventilate the patient.

During Intubation Procedure. During the intubation procedure, $46 \%$ of all respondents (225 of 490 respondents) and $43 \%$ of physicians ( 65 of 152 physician respondents) who declared having an automated mechanical chest compression device available confirmed stopping manual or mechanical chest compression, respectively.

Advanced Life Support. In patients already intubated, $68 \%$ of the physicians (326 of 479 respondents) declared never stopping manual chest compression for bagmask insufflation. Of these 326 respondents, $48 \%$ (158) declared adopting a frequency of $8-10$ insufflations $/ \mathrm{min}, 5 \%$ (16) declared using a frequency $<8$ insufflations/min, $37 \%$ (121) declared using a frequency $>10$ insufflations/min; of the 121 who used a frequency $>10$ insufflations/min, $20 \%$ (24) used a frequency $\geq 16$ insufflations/min.

During manual chest compression in patients already intubated, $87 \%$ (428 of 490 respondents) and 46\% (223 of 490 respondents) declared always or frequently using a bag-mask and a ventilator, respectively. Continuous flow insufflation with the Boussignac tube specific to CPR was cited by only $4 \%$ (18 of 490 respondents). 

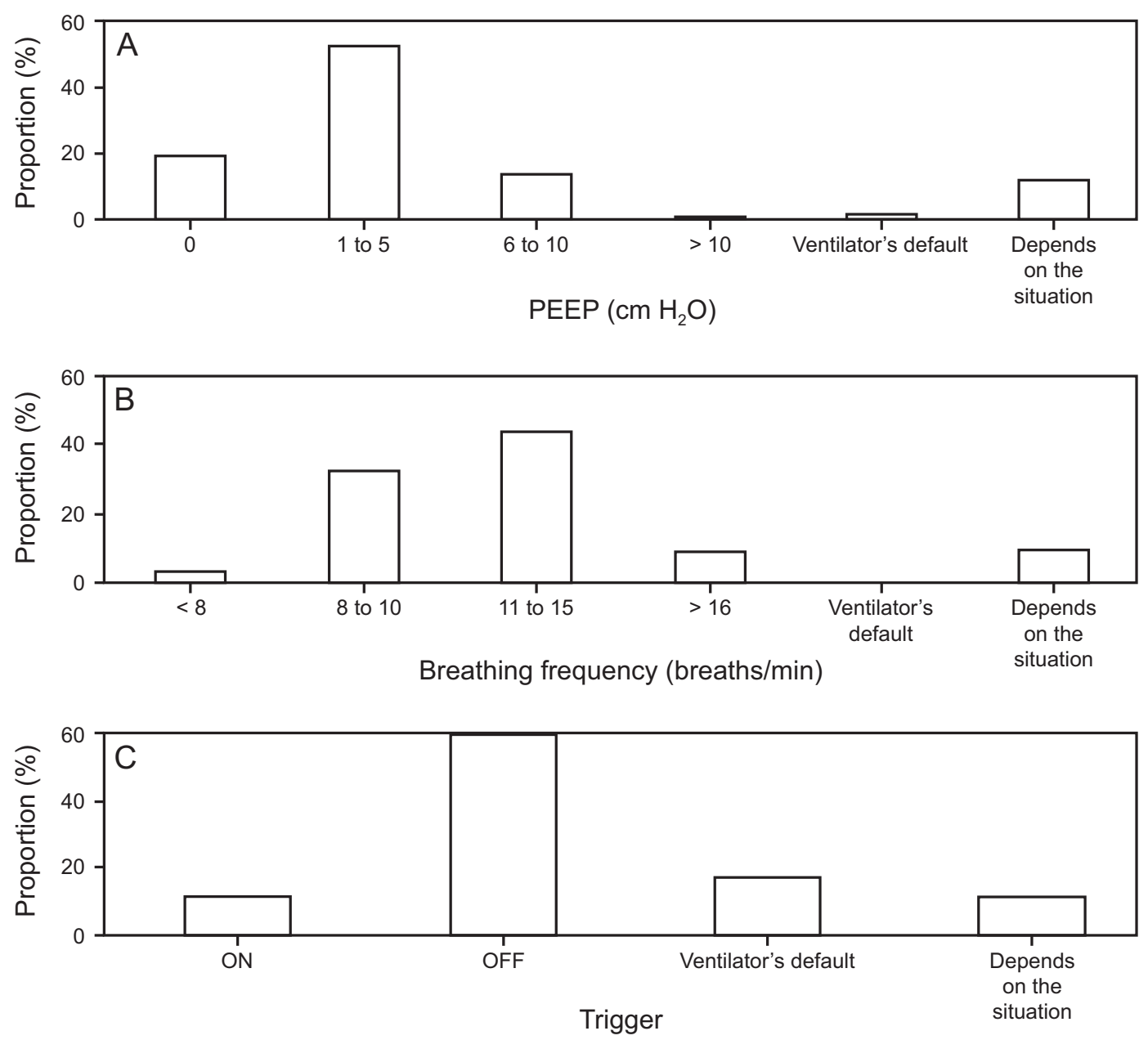

Fig. 1. Ventilator settings during cardiopulmonary resuscitation.

Ventilator Settings and Monitoring. When a ventilator was applied during CPR, the volume controlled mode was the most commonly cited mode (260 of 363 respondents, $72 \%$ ), followed by pressure controlled mode ( 85 of 363 , $23 \%$ ), and CPAP (18 of $363,5 \%$ ).

There was a marked heterogeneity regarding the ventilator settings of PEEP values (Fig. 1A), breathing frequency (Fig. 1B), and trigger (Fig. 1C). Among responders who had a ventilator available, $42 \%$ (153 of 363 respondents) declared setting $\mathrm{F}_{\mathrm{IO}_{2}}$ according to pulse oximetry $\left(\mathrm{S}_{\mathrm{pO}_{2}}\right)$, with heterogeneous $\mathrm{S}_{\mathrm{pO}_{2}}$ targets (Fig. 2A). Among those who declared setting $\mathrm{F}_{\mathrm{IO}_{2}}$ independently of $\mathrm{S}_{\mathrm{pO}_{2}}$, almost all cited an $\mathrm{F}_{\mathrm{IO}_{2}}$ of 1.0 (Fig. 2B). Monitoring practices were also heterogeneous, with $\mathrm{S}_{\mathrm{pO}_{2}}$ and end-tidal $\mathrm{CO}_{2}$ being the 2 most frequently cited variables (Fig. 3).

Specific Settings for Automatic Chest Compression Devices. During automatic mechanical chest compression in intubated patients, $18 \%$ (28 of 152) of the physicians declared always or frequently applying the 30:2 option; $62 \%$ (94 of 152) and 57\% (86 of 152) of the physicians declared always or frequently using a bag-mask and a ventilator, respectively; $12 \%$ (18 of 152) of the participants who had an automatic mechanical chest compression device available changed their ventilation monitoring options when using these devices instead of manual chest compression. In addition, 32\% (48 of 152 physicians) cited always or frequently changing their ventilation practice when using an automated chest compression device: $72 \%$ (35 of 48) of them declared adjusting ventilator settings, $36 \%$ (18 of 48) switched from manual to mechanical ventilation, and $21 \%$ (10 of 48) switched from mechanical to manual ventilation (more than one answer was possible).

Finally, only 27\% (41 of 152 physicians) declared never experiencing major problems (Fig. 4A) concerning ventilation when automated chest compression devices were used. Different strategies were proposed to face major problems (Fig. 4B). 

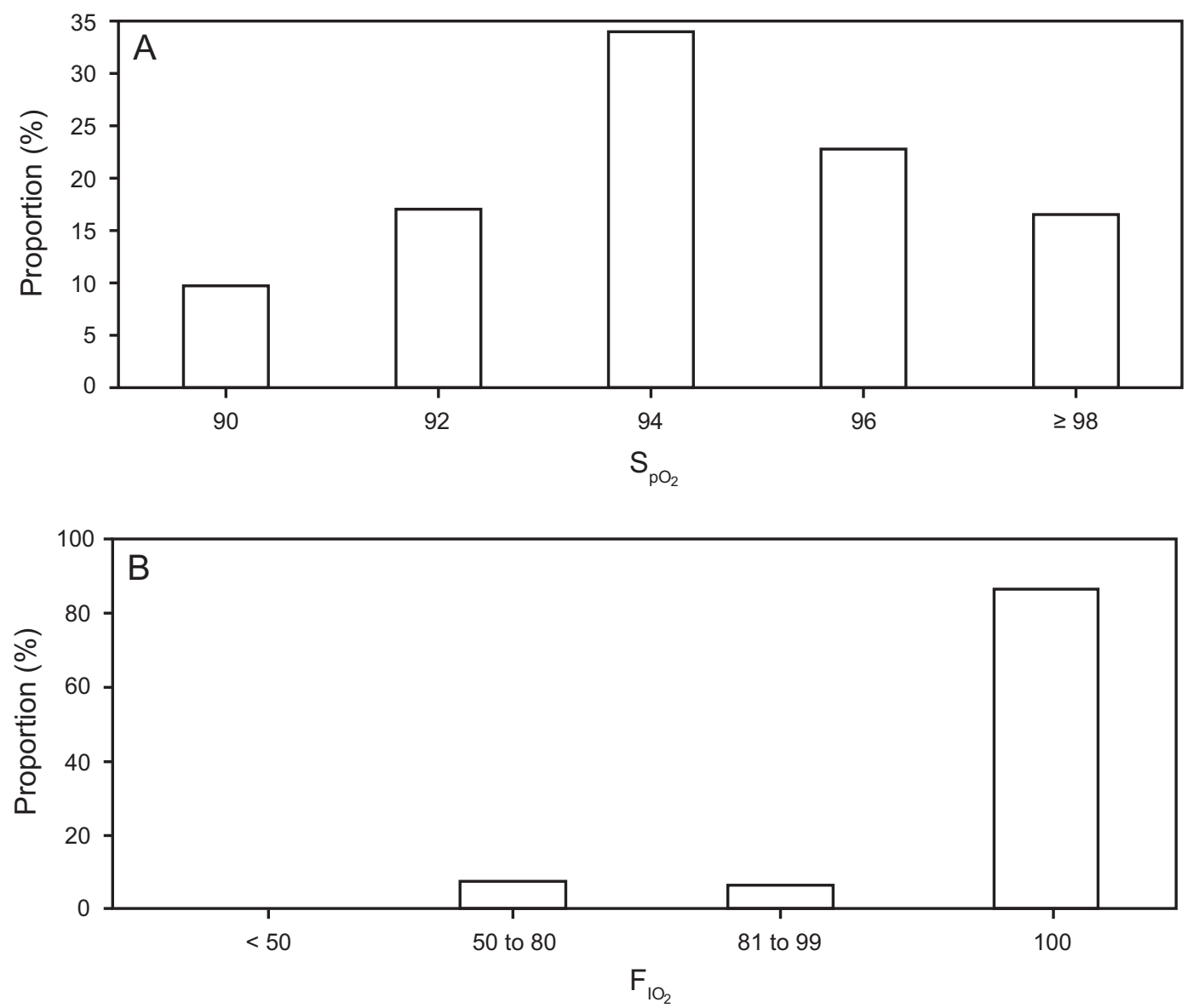

Fig. 2. $\mathrm{F}_{\mathrm{IO}_{2}}$ during cardiopulmonary resuscitation. (A) According to $\mathrm{S}_{\mathrm{pO}_{2}}$ target. (B) Independent of $\mathrm{S}_{\mathrm{pO}_{2}}$ value.

\section{Discussion}

This is the first international survey evaluating opinions and declared practices regarding ventilation during CPR. The results suggest a wide heterogeneity in practices exist. Based on the results of our survey, we can distinguish 2 major findings. First, regarding ventilation, there is a gap between declared practices and CPR recommendations in international guidelines. These observations are consistent with results of an observational study analyzing the quality of multiple parameters of $\mathrm{CPR}^{12}$ and showing that practices often do not align with published recommendations. Second, although nearly all of the respondents stated that they follow international guidelines, responses from the physicians who completed the survey were heterogeneous. Both findings could reflect the low level of evidence and the lack of specificity in the recommendations for ventilation during CPR.

\section{Available Equipment for CPR}

For ventilation, a bag-mask was the most common device available, while less than half of responders answered having a mechanical device dedicated to chest compression. A systemic review comparing manual and mechanical chest compression concluded that mechanical chest compression was not associated with harm or benefit. ${ }^{13}$ In situations such as during transportation, in the catheterization laboratory, and as a bridge to more invasive support, mechanical chest compression seems to be an interesting option, as well as when high-quality manual chest compression cannot be delivered. ${ }^{14}$ We hypothesize that automatic chest compression may render ventilation more difficult and thus interfere with clinical practices; there are few studies regarding the best ventilation strategy associated with mechanical chest compression devices, and our survey showed that the occurrence of ventilation problems is not negligible when this method of chest compression is used.

\section{Ventilation and Chest Compression}

Interestingly, more than a quarter of respondents declared adopting only continuous chest compression, highlighting the prioritization of chest compression over assisted ventilation. ${ }^{15-17}$ Some authors advocate that 


\section{International Survey of Ventilation Delivery DuRing CPR}

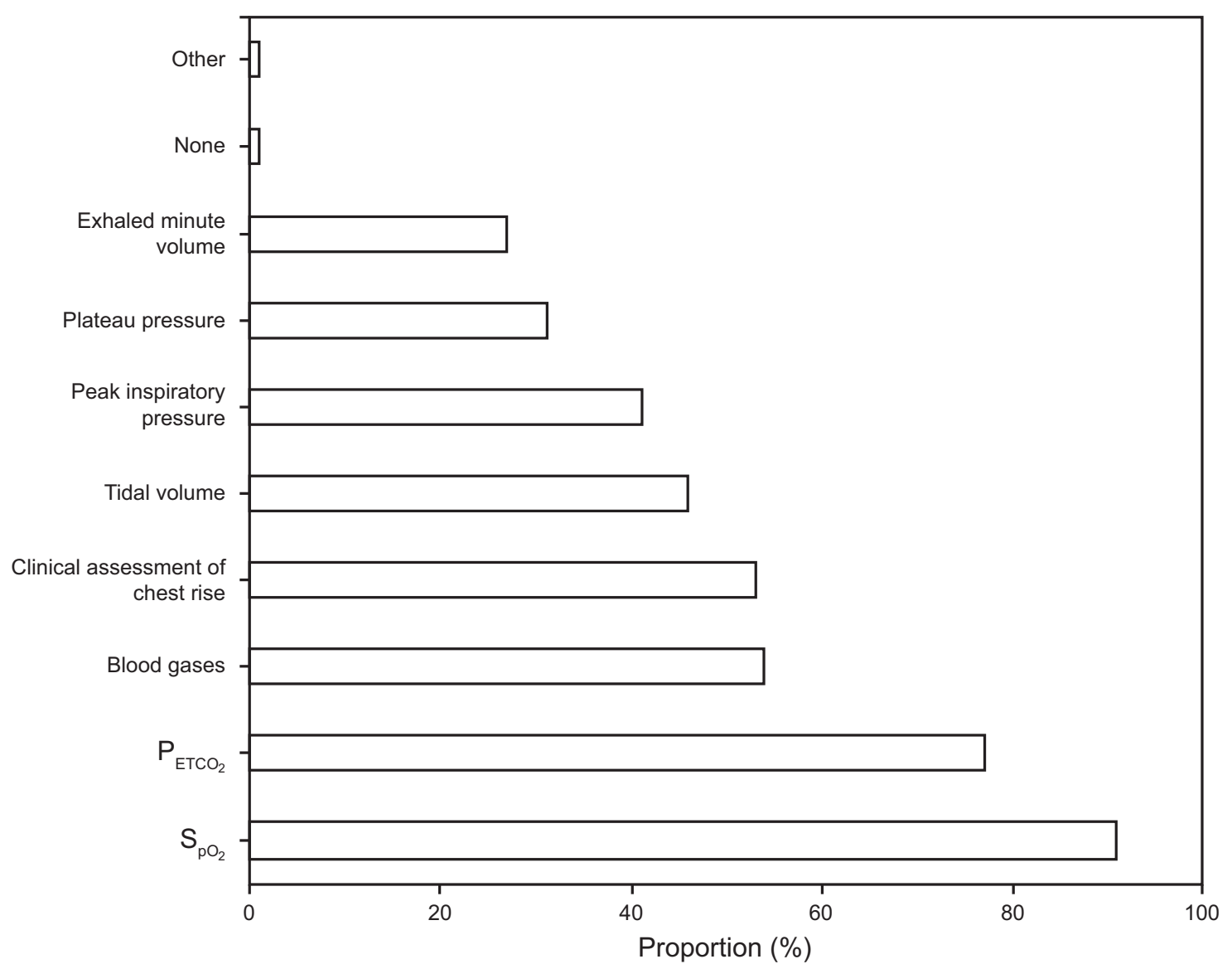

Fig. 3. Monitoring of ventilation-related variables during cardiopulmonary resuscitation. $\mathrm{P}_{\mathrm{ETCO}}=$ end-tidal carbon dioxide pressure.

ventilation is not necessary during the early phase ${ }^{18}$ or when the rescuer is alone because providing assisted ventilation may decrease the effectiveness of CPR by increasing the time without chest compression. ${ }^{19}$

Nichol et al ${ }^{20}$ published a trial in 2015 in which adults receiving CPR were treated with continuous chest compression with asynchronous ventilations delivered at a rate of 10 ventilations/min (intervention group) or with interrupted chest compression for ventilation at a ratio of 30:2, respectively (control group). The rate of survival to hospital discharge and favorable neurologic function at discharge were similar in both groups. Interestingly, the chestcompression fraction, which is an important marker of interruptions of chest compression, were high in both groups ( 0.77 in intervention group and 0.83 in control group) and above international recommendations. The mechanics driving blood flow during CPR are complex and positivepressure ventilation may play a key role in promoting better blood flow along with chest compressions if the interaction between ventilation and chest compression is well adjusted. ${ }^{21}$

We observed that almost half of the providers declared stopping chest compression for endotracheal intubation.
The optimal timing of an advanced airway placement is not well defined in the literature. Some studies demonstrated positive results when subjects were intubated ${ }^{22}$ in the first $13 \mathrm{~min},{ }^{23}$ while other studies showed better results when endotracheal intubation was avoided ${ }^{24}$ or delayed in favor of minimally interrupted chest compression. ${ }^{25}$ Recommendations regarding the relationship between chest compression and ventilation were not strictly followed by almost $20 \%$ of the providers, regardless of whether the patient was intubated.

\section{Ventilation Practice}

More than $80 \%$ of the responders declared having more than one option to support ventilation during CPR, which implies that understanding the different features of each device is important. Despite the various risks in relation to the use of a bag-mask, ${ }^{26,27}$ this device remains the most widely used to deliver assisted ventilation during CPR. Hyperventilation can be common during CPR. In the porcine CPR model, a higher ventilation rate promotes a lower coronary perfusion pressure and survival rate. ${ }^{28}$ International guidelines recommend $8-10$ breaths/min when the 

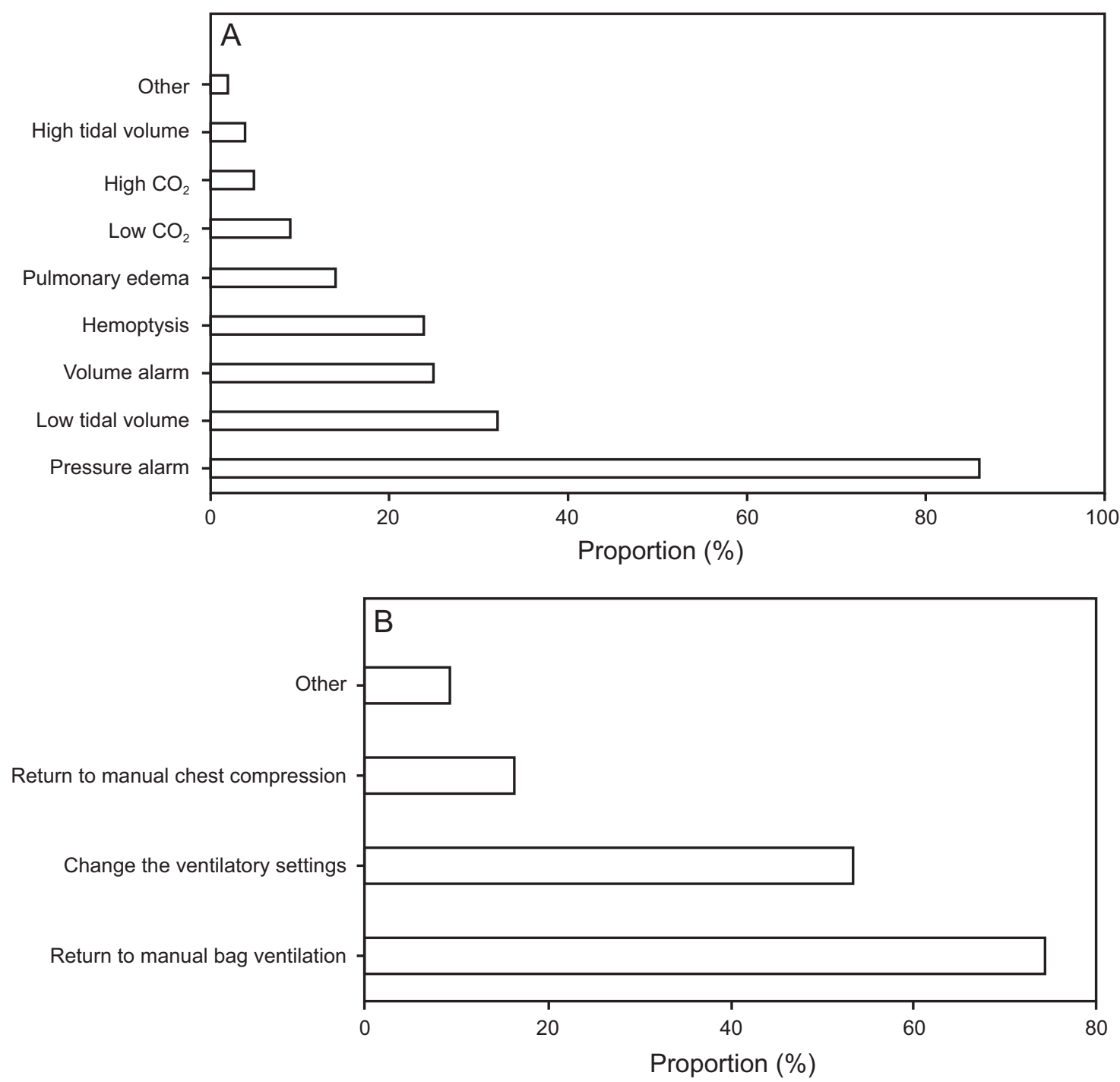

Fig. 4. Ventilation during cardiopulmonary resuscitation done with an automated chest compression device. (A) Major problems experienced. (B) Different strategies proposed to face major problems.

patient is already intubated, but we observed that almost $40 \%$ of the rescuers adopted a ventilation rate $>10$ breaths $/$ min when using a bag-mask device.

Our results indicated a large heterogeneity in setting ventilator parameters during $\mathrm{CPR}$, possibly reflecting the absence of detailed recommendations in guidelines. Furthermore, a controversy exists regarding the use of positive-pressure ventilation, ${ }^{29,30}$ which could explain the different PEEP practices observed in this survey. Regarding oxygenation, the current literature is equivocal; some studies have demonstrated that hyperoxemia is associated with higher mortality, ${ }^{31,32}$ whereas a large retrospective study did not find any relationship. ${ }^{33}$ In our survey, almost all of the providers established an $\mathrm{F}_{\mathrm{IO}_{2}}$ of 1.0 during CPR, and $35 \%$ declared adopting $\mathrm{S}_{\mathrm{pO}_{2}}$ $>96 \%$ when using pulse oximetry as a target. This high oxygenation target may carry specific risks, but further studies are needed to define the appropriate level of oxygenation during CPR.

\section{Monitoring}

In this study, the most frequently monitored parameter was $\mathrm{S}_{\mathrm{pO}_{2}}$. End-tidal $\mathrm{CO}_{2}$ was the second most cited parameter to be monitored, despite numerous limitations that render its use in routine practice complex. ${ }^{34}$ Nevertheless, end-tidal $\mathrm{CO}_{2}$ is usually considered as a physiological parameter that correlates with cardiac output and reflects the quality of chest compression during CPR.7,35 The European Resuscitation Council's 2015 guidelines highlighted the importance of end-tidal $\mathrm{CO}_{2}$ but limited its use to specific purposes. ${ }^{36}$ 


\section{International Survey of Ventilation Delivery DuRing CPR}

\section{Manual Versus Automatic Mechanical Chest Compression and Ventilation}

Ventilatory and monitoring practices were different when using an automatic mechanical chest compression device in comparison to manual chest compression. When using automatic mechanical chest compression devices, both the bag and a ventilator were frequently used. The occurrence of ventilatory problems with automatic chest compression devices appears to be frequent because most of responders declared experiencing majors issues requiring adjustment of ventilator settings.

\section{Ventilation Practices During CPR}

González et al, ${ }^{36}$ in a survey with questions similar to our survey, tried to describe ventilatory practice during CPR in children. They observed, as in our adult survey, considerable variation in the management of ventilation for children in cardiac arrest, and international recommendations were not being followed in a high percentage of cases. The results of our survey, similar to those by González et al, ${ }^{37}$ suggest that further studies of the role of ventilation during cardiac arrest are required to better understand and adjust ventilation for patients in cardiac arrest.

\section{Limitations}

We received answers from participants working in 54 countries, but $64 \%$ came from 6 countries and half of the responders were from 3 countries, which limits the worldwide representation from our survey. This survey documented opinions about practices rather than practices themselves.

The study was performed before the most recent international CPR guidelines published by the American Heart Association $^{38,39}$ and by the European Resuscitation Council. ${ }^{36,40}$ As a result, we cannot draw conclusions on the impact of the most recent recommendations, although they were very similar to the guidelines published in 2010 with regard to ventilator practices. The American Heart Association ${ }^{1,2,38,39}$ and the European Resuscitation Council 3,4,36,40 CPR guidelines are similar regarding aspects of ventilation during CPR.

\section{Conclusions}

This international survey showed that opinions and declared practices regarding the management of ventilation with chest compression differ significantly from international recommendations, even though the majority of responders stated that they follow CPR guidelines. The low level of scientific evidence and the lack of specificity in current recommendations regarding ventilation may have led to these findings. The multiplicity of available medical devices dedicated to either automated chest compression or ventilation reported in this survey may also contribute to differences in the interpretation of guidelines.

\section{ACKNOWLEDGMENTS}

The authors are grateful to the European Society of Intensive Care Medicine, the French Society of Emergency Medicine (Société Française de Médecine d'Urgence), the Brazilian Association of Intensive Care Medicine (Associação Brasileira de Medicina Intensiva), the French Language Society of Intensive Care (Société de Réanimation de Langue Française), the Japanese Society of Intensive Care Medicine, the Belgian Society of Intensive Care Medicine (Société Belge d'Anesthésie et de Réanimation), the European Artificial Ventilation Research Network, the International PanArab Critical Care Medicine Society, the European Resuscitation Council, and the European Critical Care Research NetworkEuropean Society of Intensive Care Medicine, who endorsed the survey. It was the survey of the month for the European Society of Intensive Care Medicine in December 2013. We thank Nathalie Rey, Marc Niquille, and Evangelia Akoumianaki for their important contributions to the survey formulation.

\section{REFERENCES}

1. Berg RA, Hemphill R, Abella BS, Aufderheide TP, Cave DM, Hazinski MF, et al. Part 5: adult basic life support: 2010 American Heart Association Guidelines for Cardiopulmonary Resuscitation and Emergency Cardiovascular Care. Circulation 2010;122(18 Suppl 3):S685S705.

2. Neumar RW, Otto CW, Link MS, Kronick SL, Shuster M, Callaway CW, et al. Part 8: adult advanced cardiovascular life support: 2010 American Heart Association Guidelines for Cardiopulmonary Resuscitation and Emergency Cardiovascular Care. Circulation 2010; 122(18 Suppl 3):S729-S767.

3. Deakin CD, Nolan JP, Soar J, Sunde K, Koster RW, Smith GB, et al. European Resuscitation Council Guidelines for Resuscitation 2010 Section 4. Adult advanced life support. Resuscitation 2010;81(10): 1305-1352.

4. Koster RW, Sayre MR, Botha M, Cave DM, Cudnik MT, Handley AJ, et al. Part 5: Adult basic life support: 2010 International consensus on cardiopulmonary resuscitation and emergency cardiovascular care science with treatment recommendations. Resuscitation 2010;81(Suppl 1):e48-e70.

5. Liss HP. A history of resuscitation. Ann Emerg Med 1986;15(1): 65-72.

6. Varon J, Sternbach GL. Cardiopulmonary resuscitation: lessons from the past. J Emerg Med 1991;9(6):503-507.

7. Cordioli RL, Garelli V, Lyazidi A, Suppan L, Savary D, Brochard L, et al. [Cardiopulmonary resuscitation: risks and benefits of ventilation]. Rev Med Suisse 2013;9(410):2318-2323.

8. Japanese Circulation Society Resuscitation Science Study Group. Chest-compression-only bystander cardiopulmonary resuscitation in the 30:2 compression-to-ventilation ratio era. Nationwide observational study. Circ J 2013;77(11):2742-2750.

9. Yannopoulos D, Aufderheide TP, Gabrielli A, Beiser DG, McKnite $\mathrm{SH}$, Pirrallo RG, et al. Clinical and hemodynamic comparison of 15:2 and 30:2 compression-to-ventilation ratios for cardiopulmonary resuscitation. Crit Care Med 2006;34(5):1444-1449.

10. Salas N, Wisor B, Agazio J, Branson R, Austin PN. Comparison of ventilation and cardiac compressions using the Impact Model 730 automatic transport ventilator compared to a conventional bag valve with a facemask in a model of adult cardiopulmonary arrest. Resuscitation 2007;74(1):94-101. 


\section{International Survey of Ventilation Delivery During CPR}

11. Saïssy JM, Boussignac G, Cheptel E, Rouvin B, Fontaine D, Bargues $\mathrm{L}$, et al. Efficacy of continuous insufflation of oxygen combined with active cardiac compression-decompression during out-of-hospital cardiorespiratory arrest. Anesthesiology 2000;92(6):1523-1530.

12. Abella BS, Alvarado JP, Myklebust H, Edelson DP, Barry A, O'Hearn $\mathrm{N}$, et al. Quality of cardiopulmonary resuscitation during in-hospital cardiac arrest. JAMA 2005;293(3):305-310.

13. Brooks SC, Hassan N, Bigham BL, Morrison LJ. Mechanical versus manual chest compressions for cardiac arrest. Cochrane Database Syst Rev 2014;(2):CD007260.

14. Rubertsson S. Update on mechanical cardiopulmonary resuscitation devices. Curr Opin Crit Care 2016;22(3):225-229.

15. Kellum MJ. Compression-only cardiopulmonary resuscitation for bystanders and first responders. Curr Opin Crit Care 2007;13(3):268272.

16. Dumas F, Rea TD, Fahrenbruch C, Rosenqvist M, Faxén J, Svensson $\mathrm{L}$, et al. Chest compression alone cardiopulmonary resuscitation is associated with better long-term survival compared with standard cardiopulmonary resuscitation. Circulation 2013;127(4):435-441

17. SOS-KANTO Study Group. Cardiopulmonary resuscitation by bystanders with chest compression only: an observational study. Lancet. 2007;369(9565):920-926.

18. Noc M, Weil MH, Tang W, Turner T, Fukui M. Mechanical ventilation may not be essential for initial cardiopulmonary resuscitation. Chest 1995;108(3):821-827.

19. Ewy GA. Chest compression only cardiopulmonary resuscitation for primary cardiac arrest. Circulation 2016;134(10):695-697.

20. Nichol G, Leroux B, Wang H, Callaway CW, Sopko G, Weisfeldt M, et al. Trial of continuous or interrupted chest compressions during CPR. N Engl J Med 2015;373(23):2203-2214.

21. Georgiou M, Papathanassoglou E, Xanthos T. Systematic review of the mechanisms driving effective blood flow during adult CPR. Resuscitation 2014;85(11):1586-1593.

22. Jennings PA, Cameron P, Walker T, Bernard S, Smith K. Out-ofhospital cardiac arrest in Victoria: rural and urban outcomes. Med J Aust 2006;185(3):135-139.

23. Shy BD, Rea TD, Becker LJ, Eisenberg MS. Time to intubation and survival in prehospital cardiac arrest. Prehosp Emerg Care 2004; 8(4):394-399.

24. Dumot JA, Burval DJ, Sprung J, Waters JH, Mraovic B, Karafa MT, et al. Outcome of adult cardiopulmonary resuscitations at a tertiary referral center including results of "limited" resuscitations. Arch Intern Med 2001;161(14):1751-1758.

25. Bobrow BJ, Ewy GA, Clark L, Chikani V, Berg RA, Sanders AB, et al. Passive oxygen insufflation is superior to bag-valve-mask ventilation for witnessed ventricular fibrillation out-of-hospital cardiac arrest. Ann Emerg Med. 2009;54(5):656-662.e1.

26. Piegeler T, Roessler B, Goliasch G, Fischer H, Schlaepfer M, Lang $\mathrm{S}$, et al. Evaluation of six different airway devices regarding regurgitation and pulmonary aspiration during cardio-pulmonary resuscitation (CPR): a human cadaver pilot study. Resuscitation 2016;102: 70-74.

27. Ocker H, Wenzel V, Schmucker P, Dörges V. Effectiveness of various airway management techniques in a bench model simulating a cardiac arrest patient. J Emerg Med 2001;20(1):7-12.
28. Aufderheide TP, Sigurdsson G, Pirrallo RG, Yannopoulos D, McKnite $\mathrm{S}$, von Briesen $\mathrm{C}$, et al. Hyperventilation-induced hypotension during cardiopulmonary resuscitation. Circulation 2004;109(16): 1960-1965.

29. Ido Y, Goto H, Lavin MJ, Robinson JD, Mangold JV, Arakawa K. Effects of positive end-expiratory pressure on carotid blood flow during closed-chest cardiopulmonary resuscitation in dogs. Anesth Analg 1982;61(7):557-560.

30. Cordioli RL, Lyazidi A, Rey N, Granier JM, Savary D, Brochard L, et al. Impact of ventilation strategies during chest compression. An experimental study with clinical observations. J Appl Physiol (1985) 2016;120(2):196-203.

31. Kilgannon JH, Jones AE, Shapiro NI, Angelos MG, Milcarek B, Hunter K, et al. Association between arterial hyperoxia following resuscitation from cardiac arrest and in-hospital mortality. JAMA 2010;303(21):2165-2171.

32. Kilgannon JH, Jones AE, Parrillo JE, Dellinger RP, Milcarek B, Hunter K, et al. Relationship between supranormal oxygen tension and outcome after resuscitation from cardiac arrest. Circulation 2011; 123(23):2717-2722.

33. Bellomo R, Bailey M, Eastwood GM, Nichol A, Pilcher D, Hart GK, et al. Arterial hyperoxia and in-hospital mortality after resuscitation from cardiac arrest. Crit Care 2011;15(2):R90.

34. Heradstveit BE, Sunde K, Sunde GA, Wentzel-Larsen T, Heltne JK. Factors complicating interpretation of capnography during advanced life support in cardiac arrest: a clinical retrospective study in 575 patients. Resuscitation 2012;83(7):813-818.

35. Pantazopoulos C, Xanthos T, Pantazopoulos I, Papalois A, Kouskouni E, Iacovidou N. A review of carbon dioxide monitoring during adult cardiopulmonary resuscitation. Heart Lung Circ 2015;24(11): 1053-1061.

36. Soar J, Callaway CW, Aibiki M, Böttiger BW, Brooks SC, Deakin CD, et al. Part 4: Advanced life support: 2015 international consensus on cardiopulmonary resuscitation and emergency cardiovascular care science with treatment recommendations. Resuscitation 2015; 95:e71-e120

37. González R, Pascual L, Sava A, Tolón S, Urbano J, López-Herce J. Ventilation during cardiopulmonary resuscitation in children: a survey on clinical practice. World J Pediatr 2017;13(6):544-550.

38. Kleinman ME, Brennan EE, Goldberger ZD, Swor RA, Terry M, Bobrow BJ, et al. Part 5: Adult basic life support and cardiopulmonary resuscitation quality: 2015 American Heart Association guidelines update for cardiopulmonary resuscitation and emergency cardiovascular care. Circulation 2015;132(18 Suppl 2):S414-S435.

39. Link MS, Berkow LC, Kudenchuk PJ, Halperin HR, Hess EP, Moitra VK, et al. Part 7: adult advanced cardiovascular life support: 2015 American Heart Association guidelines update for cardiopulmonary resuscitation and emergency cardiovascular care. Circulation 2015; 132(18 Suppl 2):S444-S464

40. Perkins GD, Travers AH, Berg RA, Castren M, Considine J, Escalante R, et al. Part 3: Adult basic life support and automated external defibrillation: 2015 international consensus on cardiopulmonary resuscitation and emergency cardiovascular care science with treatment recommendations. Resuscitation 2015;95:e43-e69. 